\title{
Úlcera de Marjolin y carcinoma espinocelular en paciente con antecedente de quemaduras
}

\author{
Marjolin ulcer and squamous cell carcinoma in patient with an antecedent of burns \\ Dr. Iram González-Vargas,* Dr. Luis Tamez-Pedroza, ${ }^{\ddagger}$ Dr. José Ángel Facio-Treviño, ${ }^{\ddagger}$ \\ Dr. Carlos Pacheco-Molina, ${ }^{\S}$ Dr. Luis Alberto Treviño-García, ${ }^{\mathbb{I}}$ \\ Dr. Marco Antonio Treviño-Lozano, " Dr. Mauricio Manuel García-Pérez ${ }^{* *}$
}

Palabras clave: Úlcera de Marjolin, heridas crónicas, carcinoma espinocelular, quemaduras, carcinoma basocelular.

Keywords: Marjolin ulcer, chronic wounds, squamous cell carcinoma, burns, basal cell carcinoma.

* Cirujano Plástico adscrito al Servicio de Cirugía Plástica y Reconstructiva, Hospital Universitario de Monterrey «Dr. José Eleuterio González».

México.

* Residente de Cirugía

General, Hospital

Universitario de

Monterrey «Dr. José

Eleuterio González».

México.

$\S$ Residente de

Cirugía Oncológica,

Instituto Nacional de

Cancerología. México.

"Residente de

Cirugía Plástica

y Reconstructiva,

Hospital Universitario

de Monterrey «Dr. José

Eleuterio González».

México.

॥ Cirujano Oncólogo

adscrito de Cirugía

Oncológica, Hospital

Universitario de

Monterrey «Dr. José

Eleuterio González».

México.

\section{RESUMEN}

La úlcera de Marjolin es una lesión crónica que desarrolla algún tipo de cáncer, principalmente carcinoma espinocelular y basocelular. Aunque se han reportado otros tipos de cáncer en éstas lesiones crónicas asociadas a quemaduras, traumatismos, úlceras venosas, úlceras por presión y otras heridas crónicas. Presentamos el caso de una paciente de 48 años que acudió a consulta de cirugía plástica y cirugía oncológica por presentar dos lesiones ulceradas en extremidad superior izquierda y extremidad inferior derecha. La paciente tenía antecedente de quemadura a los cinco años en la cara, cuello y extremidades superiores e inferiores, que se manejaron con injertos cutáneos. Se realizaron biopsias de ambas lesiones que reportaron carcinoma espinocelular. Cirugía oncológica realizó amputación transradial izquierda, resección amplia con bordes libres de tumor en el muslo derecho y vaciamiento ganglionar inguinal derecho; y cirugía plástica cubrió el defecto del muslo derecho con injerto cutáneo. Acudió a consulta a los cuatro meses de la cirugía con la herida de la extremidad superior bien cicatrizada, el injerto de piel en muslo bien integrado, sin datos de infección, con adenopatías axilares palpables y la región inguinal sin adenopatías.

\section{ABSTRACT}

Marjolin's ulcer is a chronic lesion that develops some types of cancer, mainly squamous cell and basal cell carcinoma, although other types of cancer have been reported in these chronic lesions associated with burns, trauma, venous ulcers, pressure ulcers and other chronic wounds. We present the case of a 48-year-old patient who came to the plastic surgery and oncological surgery consultation with two ulcerated lesions in the upper left limb and the lower right limb. The patient had an antecedent of burns in the face, neck, and upper and lower extremities when she was five years-old, which were managed with skin grafts. Biopsies of both lesions that reported squamous cell carcinoma were performed. Oncological surgery doctors performed left transradial amputation, wide resection with tumor-free borders in the right thigh and right inguinal lymph node dissection, and plastic surgery doctors covered the right thigh defect with skin graft. She came to the consulting room four months after surgery with a well-healed upper limb wound, a well-integrated thigh skin graft, no evidence of infection, palpable axillary lymphadenopathy and the inguinal region, free of lymphadenopathy.

\section{INTRODUCCIÓN}

$\mathrm{S}^{\mathrm{e}}$ le llama úlcera de Marjolin a la lesión caracterizada por heridas crónicas asociadas principalmente a quemaduras, úlceras venosas, úlceras por presión y otras heridas que desarrollan algún tipo de cáncer; suelen ser de evolución lenta, con un tiempo promedio de 25 años. ${ }^{1}$ En una revisión sistemática realizada en 2018 sobre los casos publicados, Abdi y colegas, ${ }^{2}$ reportaron 599 casos de úlceras de Marjolin, donde el $82 \%$ de los pacientes pertenecían a países de ingresos bajos y medios, el $65 \%$ de las úlceras fueron precedidas por quemaduras,

Citar como: González-Vargas I, Tamez-Pedroza L, Facio-Treviño JÁ, Pacheco-Molina C, Treviño-García LA, TreviñoLozano MA et al. Úlcera de Marjolin y carcinoma espinocelular en paciente con antecedente de quemaduras. Cir Plast. 2021; 31 (2): 72-76. https://dx.doi.org/10.35366/102749 
** Cirujano Plástico, Jefe del Servicio de Cirugía Plástica y Reconstructiva, Hospital Universitario de Monterrey «Dr. José Eleuterio González». México.

Recibido: 24 marzo 2021 Aceptado: 17 mayo 2021 los tratamiento más usados fueron resección quirúrgica (71\%), amputación (21\%), radioterapia $(2 \%)$ y quimioterapia $(1 \%)$. El tratamiento con quimioterapia y radioterapia se reserva para paciente que tienen una contraindicación quirúrgica, o como tratamiento coadyuvante en tumores con resección incompleta, metástasis ganglionares o recidivas tumorales. ${ }^{3}$

Presentaremos el caso de una paciente que acudió por presentar dos lesiones en extremidades superior e inferior secundarias a quemaduras por fuego en la infancia, las cuales presentaron malignización con reporte de carcinoma espinocelular.

\section{CASO CLÍNICO}

Mujer de 48 años sin antecedentes personales patológicos, con antecedente de quemaduras de segundo y tercer grado en cuello, extremidades superiores e inferiores durante su infancia a los cinco años, con una extensión aproximada del 30\% de la superficie corporal total, que fue referida a nuestro hospital por presentar dos lesiones ulceradas y fétidas en la extremidad superior izquierda y muslo derecho, las cuales se asentaban sobre la cicatriz de las quemaduras previas. La paciente refirió que dichas lesiones fueron aumentando de tamaño en forma gradual y desconocía el tiempo de evolución. Se realizaron biopsias incisionales de ambas lesiones y se citó en siete días para manejo quirúrgico definitivo.

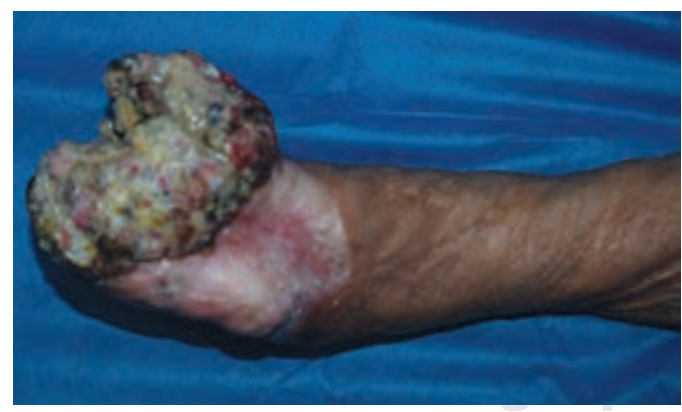

Figura 1: Mano izquierda con pérdida de la arquitectura a expensas de tumoración en su porción distal, de aspecto exofítico, de $8 \times 5 \times 5 \mathrm{~cm}$, purulenta, de color café rojizo, alternando con zonas de color café claro con natas purulentas, con áreas de necrosis, olor fétido, no dolorosa a la palpación.

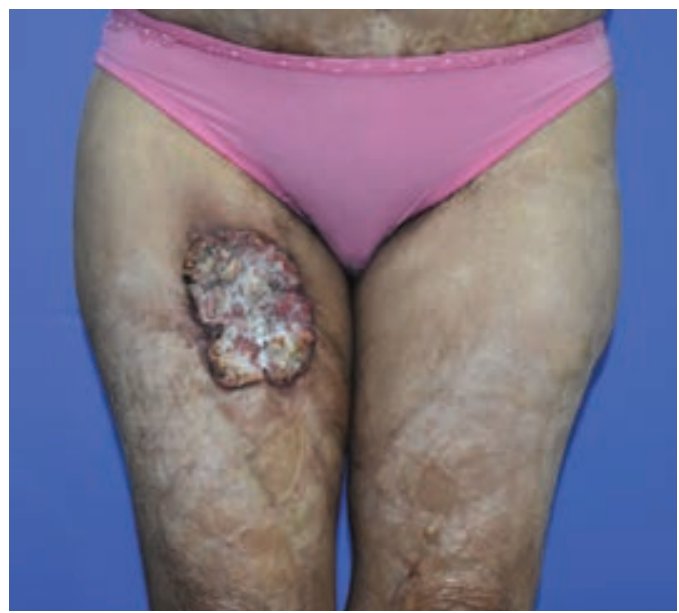

Figura 2: Dermatosis que afecta la cara anterior del muslo derecho a nivel del tercio proximal, con medidas de $7.3 \times 0.8 \times 11.0 \mathrm{~cm}$, constituida por una úlcera con aparente tejido de granulación en su superficie, zonas de tejido blanco amarillento de aspecto vegetante; bordes elevados, hiperpigmentada en la periferia y asentada sobre la cicatriz atrófica, con zonas hipopigmentadas, sugestiva de evolución crónica.

A la exploración física se observó dermatosis en mano izquierda, de la que afectaba la porción distal, constituida por una neoformación de aspecto exofítico de $8 \times 5 \times 5$ $\mathrm{cm}$, color café rojizo, alternando con zonas de color café claro, natas purulentas con áreas de necrosis, de bordes irregulares bien definidos, con olor fétido, no dolorosa a la palpación (Figura 1). Al resto de la exploración física, presentaba adenomegalias palpables en axila. En la extremidad inferior derecha se observaba dermatosis que afectaba la cara anterior del muslo a nivel del tercio proximal, con medidas de $7.3 \times 0.8 \times 11.0 \mathrm{~cm}$, constituida por una úlcera con aparente tejido de granulación en su superficie, zonas de tejido blanco amarillento de aspecto vegetante, con bordes elevados, hiperpigmentada en la periferia y asentada sobre la cicatriz atrófica, con zonas hipopigmentadas, sugestiva de evolución crónica (Figura 2). No presentaba adenomegalias palpables en la región inguinal y poplítea. Se realizó una tomografía que evidenció adenopatías en región axilar derecha; la más representativa con medidas de $1.6 \times$ $1.2 \mathrm{~cm}$ y en región inguinal superficial dere- 
cha, con medidas de $1.4 \times 1.5 \times 2.0 \mathrm{~cm}$, sin evidencia de enfermedad a distancia.

El reporte de la biopsia incisional de ambas lesiones reveló múltiples fragmentos con áreas de epitelio escamoso, con atipia franca que invadía el tejido estromal, las células escamosas con pérdida de la maduración que se acompañaba con abundantes perlas córneas y queratinización individual y de un proceso inflamatorio crónico ulcerado con datos de fibrina. Todo ello compatible con carcinoma espinocelular moderadamente diferenciado.

La paciente acudió a consulta donde se decidió enviar a urgencias. Se realizó amputación transradial de la mano izquierda (Figura 3) con borde óseo, borde vascular, borde de piel y tejidos blandos negativos para neoplasia. Se realizó resección de lesión en muslo derecho y linfadenectomía inguinal derecha, con bordes quirúrgicos libres de neoplasia superior a 2.3 $\mathrm{cm}$, inferior a $1.7 \mathrm{~cm}$, medial a $0.7 \mathrm{~cm}$, lateral a $2.1 \mathrm{~cm}$ y profundo a $0.3 \mathrm{~cm}$; además de colocación de injerto de espesor parcial proveniente del muslo contralateral.

La paciente fue referida a radiooncología para valorar radioterapia al egreso y cita de seguimiento en cirugía plástica para seguimiento, a las cuales no acudió. Se contactó con la paciente y acudió a los cuatro meses, refiriendo no haber podido acudir a radioterapia y consultas de seguimiento por motivos económicos. A la exploración física, la herida de extremidad superior estaba bien cicatrizada, (Figura 3) en muslo el injerto de piel integrado, sin datos de

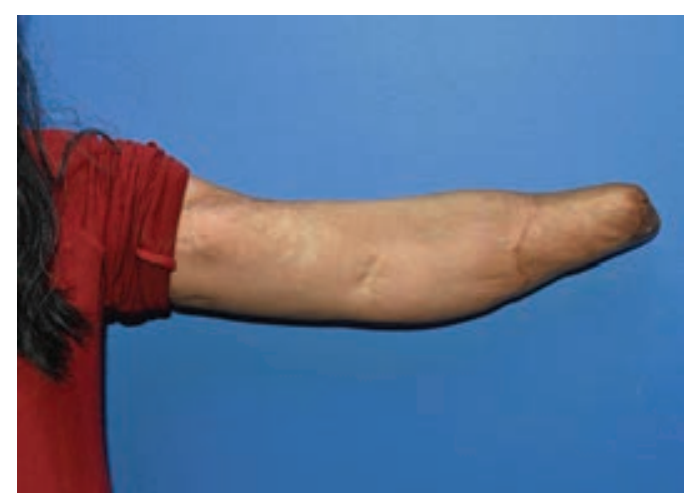

Figura 3: Extremidad superior izquierda con amputación de mano izquierda a nivel transradial a los cuatro meses de cirugía.

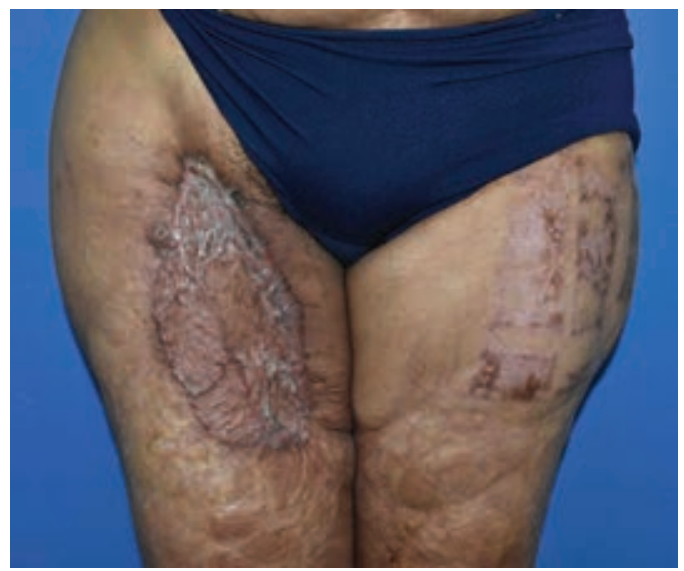

Figura 4: Fotografía de injerto en muslo de extremidad inferior izquierda a los cuatro meses de la cirugía.

infección, con adenopatías axilares palpables y región inguinal sin adenopatías (Figura 4). Se refirió a radiooncología médica nuevamente y se citó en seis meses para revaloración.

\section{DISCUSIÓN}

El término de úlcera de Marjolin se usa en la actualidad para referirse a lesiones o heridas crónicas que presentan algún tipo de malignización. Quien describió éste tipo de lesiones fue el cirujano francés Dr. Jean Nicolas Marjolin, en 1828. ${ }^{4}$ Marjolin no describió este tipo de lesiones como malignas y no fue hasta 1902 que Da Costa reportó dos casos de úlceras venosas en extremidades inferiores que malignizaron, y las describió como úlceras de Marjolin. ${ }^{5}$ Después, en 1990, el Dr. Hahn reportó 19 casos de úlcera de Marjolin en un periodo de 19 años, siendo lo más común una quemadura como antecedente, con un periodo de latencia de 31.5 años entre la lesión y el cáncer. ${ }^{6}$ En 2012, Chalya ${ }^{7}$ reportó 59 casos de ulceras de Marjolin, donde la población más común fueron hombres en comparación de mujeres con relación 2:1. La lesión más común previo a malignizar fue quemadura en el $89.3 \%$ de los casos; la media de aparición entre la quemadura y el cáncer fue de $11.34 \pm 6.14$ años, aunque hay casos reportados hasta 67 años después. ${ }^{8}$ El sitio más común de aparición de úlceras de Marjolin fue en las extremidades inferiores (42.9\%) y el cáncer espinocelular fue el más común en las 
lesiones en el $91.1 \%$ de los casos. ${ }^{7}$ La mayoría de médicos que han investigado la formación de cáncer en lesiones crónicas concuerdan que el mejor tratamiento preventivo es remover el tejido afectado e injertar piel sana en los sitios dañados, tanto en quemaduras como en lesiones de heridas crónicas que no sanan. ${ }^{9}$

Se recomienda realizar el diagnóstico con biopsias de las lesiones. Bozkurt, ${ }^{10}$ recomienda realizar una biopsia si la tumoración mide menos de $2.5 \mathrm{~cm}$; si mide entre 2.5 a $5 \mathrm{~cm}$, se recomienda un mínimo de cuatro biopsias (a las 3, 6, 9 y 12 horas, conforme a la posición del reloj). En lesiones mayores de $5 \mathrm{~cm}$ se recomienda seis biopsias (a las 2, 4, 6, 8, 10 y 12 horas, conforme a la posición del reloj). En caso de tener una biopsia positiva se recomienda realizar estudios de imagen como ultrasonido para descartar metástasis a ganglios linfáticos, tomografía computarizada (TC) para valorar extensión a tejido óseo o ganglionar, imagen por resonancia magnética (IRM) para valorar tejidos blandos, tomografía por emisión de positrones PET/TC o PET/IRM para valorar metástasis a distancia, según sea el caso del paciente. ${ }^{4}$

El principal tipo de cáncer asociado a úlceras de Marjolin es el carcinoma espinocelular en $75-96 \%$ de los casos, basocelular en 1-25\% y también han reportado la presencia de melanoma, sarcoma osteogénico, fibrosarcoma y liposarcoma. ${ }^{7,11}$

El tratamiento de elección para este tipo de lesiones consiste en la resección con márgenes de 4-6 mm que lleva a un porcentaje de cura hasta del $90 \%$ de los casos. La cirugía de Mohs reporta un 99\% de cura a cinco años. ${ }^{12}$ Cuando se involucran ganglios linfáticos palpables, se recomienda realizar una biopsia por punción con aguja fina o biopsia escisional con sección congelada para determinar el tratamiento. ${ }^{12} \mathrm{En}$ pacientes que presentan enfermedad avanzada, con mal pronóstico o que no son candidatos quirúrgicos se puede ofrecer tratamiento con radioterapia o quimioterapia. ${ }^{11} \mathrm{La}$ amputación está indicada en pacientes con afectación profunda de hueso o articulaciones. ${ }^{7}$

El pronóstico depende de factores como edad del paciente, tipo de lesión maligna que presenta, tamaño, presencia de metástasis, recurrencias y tipo de tratamiento empleado en cada paciente. ${ }^{11}$ La tasa de supervivencia a cin- co años es del 90\% en carcinoma espinocelular sin metástasis ganglionar y en pacientes con presencia de metástasis del $39 \%$. $^{7}$ Las tasas de recurrencia son mayores en carcinoma espinocelular, comparado con las otras neoplasias que se presentan en las úlceras crónicas. ${ }^{13}$

\section{CONCLUSIÓN}

El rango de edad de presentación reportado en la literatura varía de cinco a 67 años después de la lesión, principalmente en quemaduras, lesiones traumáticas, úlceras venosas, úlceras por presión y otras lesiones, por lo que es importante tener en mente este tipo de complicaciones en el seguimiento por consulta de pacientes con heridas que no mejoran. Tenemos que plantear el manejo quirúrgico con resección e injerto de piel o rotación de colgajo local para disminuir el riesgo de malignización. Es necesario el seguimiento y reporte de más pacientes y tratamientos para este tipo de enfermos con heridas crónicas. En nuestro caso, la paciente presentaba enfermedad avanzada sin seguimiento y se optó por amputación de la extremidad superior, resección de la tumoración en muslo e injerto de piel y vaciamiento ganglionar inguinal. Es necesario explicar la importancia del seguimiento a largo plazo en pacientes quemados, sobre todo en pacientes de bajos recursos que tienen el riesgo de no contar con un seguimiento a largo plazo.

\section{REFERENCIAS}

1. Baldursson B, Sigurgeirsson B, Lindelof B. Venous leg ulcers and squamous cell carcinoma: a large-scale epidemiological study. Br J Dermatol 1995; 133 (4): 571-574.

2. Abdi MA, Yan M, Hanna TP. Systematic Review of Modern Case Series of Squamous Cell Cancer Arising in a Chronic Ulcer (Marjolin's Ulcer) of the Skin. JCO Glob Oncol 2020; (6): 809-818.

3. Hernández Martín A, Echeverría Iturbe Celina. Carcinoma espinocelular. Piel 2003; 18 (7): 364-376.

4. Tian J, Zou JP, Xiang XF, Tang JB, Cheng B. Marjolin's ulcer: A case report and literature review. World Acad Sci J 2020; 3 (1): 1-6.

5. Da Costa JC. III. Carcinomatous Changes in an Area of Chronic Ulceration, or Marjolin's Ulcer. Ann Surg 1903; 37 (4): 496-502.

6. Hahn SB, Kim DJ, Jeon CH. Clinical study of Marjolin's ulcer. Yonsei Med J 1990; 31 (3): 234-241.

7. Chalya PL, Mabula JB, Rambau P, Mchembe MD, Kahima KJ, Chandika AB et al. Marjolin's ulcers at a 
university teaching hospital in Northwestern Tanzania: a retrospective review of 56 cases. World J Surg Oncol 2012; 10 (1): 38.

8. Iqbal FM, Sinha Y, Jaffe W. Marjolin's ulcer: A rare entity with a call for early diagnosis. BMJ Case Rep 2015; 2015: 10-13.

9. Ochenduszkiewicz U, Matkowski R, Szynglarewicz B, Kornafel J. Marjolin's ulcer: malignant neoplasm arising in scars. Reports Pract Oncol Radiother 2006; 11 (3): 135-138.

10. Bozkurt M, Kapi E, Kuvat SV, Ozekinci S. Current concepts in the management of Marjolin's ulcers: outcomes from a standardized treatment protocol in 16 cases. J Burn Care Res 2010; 31 (5): 776-780.

11. Jiménez HF, González GM, Douriet MFA. Cirugía e injertos autólogos en el tratamiento de la úlcera de Marjolin: informe de un caso. Dermatol Cosmet Med Quir 2014; 12 (2): 114-117.
12. Di Martino Ortiz B, Riveros R, Martinez Braga G, Medina de Sosa R, Rodríguez Masi M, Knopfelmacher O et al. Marjolin ulcer: a case report. Our Dermatology Online 2014; 5 (1): 51-53.

13. Pavlovic S, Wiley E, Guzman G, Morris D, Braniecki M. Marjolin ulcer: an overlooked entity. Int Wound J 2011; 8 (4): 419-424.

Conflicto de intereses: Los autores declaran no tener conflicto de intereses.

Correspondencia:

Dr. Iram González-Vargas

Gonzalitos S/N, Mitras Centro, 64460 Monterrey, N.L., México.

E-mail: dr.iram.gzz@gmail.com 